little book describes the work of the pioneering rehabilitation centre in Copenhagen. It provides a helpful guide to those developing an interest in the subject. It also provides useful information for all health professionals and should be required reading for every medical and nursing student. The horrors it describes and illustrates are not for the faint-hearted, but sadly torture will not go away because we ignore it. On the contrary, such an attitude creates the very atmosphere in which it is more likely to thrive. Although written by a nurse, there is great emphasis upon a team approach but the duties of individual team members are not set out in detail. It is not always easy to understand the contribution which particular professional skills make to the overall outcome, although the importance of working together and moving the survivor from a position of total dependence to one in which she/he is prepared to assume control over her/his own life and rehabilitation programme, are well brought out.

The book would have benefited from a 'word wash' by a native English speaker, since the nuances are sometimes difficult to understand. Those who are prepared to make the effort to discover them will be richly rewarded.

J STUART HORNER Member, Torture Working Party, British Medical Association

[See also the supplement published with this issue of the journal. Editor.]

\section{The Abuse of Casuistry: A History of Moral Reasoning}

Albert $\mathbf{R}$ Jonsen and Stephen Toulmin, 429 pages, Berkeley and Los Angeles, US\$14.95, University of California Press, 1988

Give a certain kind of dog a bad name and, with a bit of luck, you might succeed in persuading the government to introduce legislation against that particular breed. At a later stage, members of a certain school of thought - perhaps more than one school - might convince the government that such legislation was inappropriate for some reason. They might even convince the government of the breed's innocence. So much for dogs, but what happens when it is a school of thought that gets the bad name?

Casuistry has had a bad name for quite a long time, and Jonsen and Toulmin believe it is time to put the record straight. The peculiar task of their book, as they put it, is not to rehabilitate the word but rather the art to which the word 'casuistry' refers: 'the practical resolution of particular moral perplexities, or "cases of conscience". They note that in recent times it has again become acceptable to discuss specific circumstances and cases. This state of affairs, they feel, has come about almost inadvertently as a byproduct of our preoccupation with professional ethics, notably medical ethics. However, although we can see a new casuistry at work in arguments advanced about various issues, 'the philosophical disrepute into which "case ethics" has fallen means that the forms and methods proper to such arguments are not widely discussed or understood'.

The authors make a notable contribution towards filling this gap. Whilst tracing the roots of casuistry in antiquity, and giving an ample history of the subject, they succeed in covering in some depth various arguments about the difference between the kind of reasoning used in geometry and that practical reasoning involved in ethics. They also provide ample descriptions and analyses of how the casuists worked. Whilst admitting that there was at times a fair amount of misuse of the art, they hold that Pascal's famous attack upon it in The Provincial Letters went too far because he attacked casuistry as a whole instead of merely trying to rectify its misuse. In their opinion, the abuse of casuistry - in the sense of the scorn that has been poured on it since Pascal's time - has been almost entirely unjustified.

As for the present day, they ask how there can be a renewed casuistry in a culture which lacks the necessary institutions. Some of these institutions, they believe, have come into existence, notably in the world of bioethics. Although much of what they say in this regard refers specifically to the United States, it should be clear to those actively involved in bioethics that somewhat similar things could be said about other parts of the world.

There are numerous discussions of bioethical issues in this book. Indeed the very occasion that led to its being written was the authors' involvement in the work of The National Commission for the Protection of Human Subjects of Biomedical and Behavioral Research in the United States, an outcome of that work having been a casuistry for distinguishing acceptable and unacceptable ways of involving people as subjects in medical or behavioural research. The book should therefore be of enormous interest to anyone with a serious interest in bioethics or, indeed, any other branch of ethics.

BERNARD HOOSE

Research Fellow in Christian Ethics, Heythrop College, 11-13 Cavendish Square, London WIM OAN.

\section{Proceed with Caution: Predicting Genetic Risks in the Recombinant DNA Era}

Neil A Holtzman, 303 pages, Baltimore and London, $£ 23.50 \mathrm{hc}, £ 9.55 \mathrm{sc}$, Johns Hopkins University Press, 1989

Neil Holtzman is Professor of Pediatric at the Johns Hopkins University Schoo of Medicine and has special interests ir the management of inborn errors of metabolism and in the education of the public and of doctors. The concept of this book arose out of a report in the mid-1980s on genetic susceptibilities to environmental agents.

For description it is useful to divide the book into three main parts. In the introduction the scope of the book is summarised and the principles of inheritance and of the role of genes in disease are taught (chapters 1 to 3,56 pages). Then follow three chapters dealing with the new genetics and based largely on DNA techniques (pages 57 to 138). The sixth chapter describes the transfer of technology from research to clinical and commercial application. The last three chapters cover the factors involved in the development of widespread genetic screening, discussions of the philosophy of genetic testing, 'In whose best interest', and 'What is going to be done?'.

First let me say how appropriate such a publication is and what a wealth of information Holtzman has collected. He writes in an idiosyncratic style but is very readable. At the end of the book many references are given along with copious notes and a huge sprinkling of personal communications which would be difficult to check. In covering such a wide field, Holtzman has often cut 
corners and has slipped into errors which confuse. Few geneticists for example, would feel happy with the sentence: 'The genes occupying identical loci on homologous chromosomes also are homologous' (pp $9 / 10$ ). This could well confuse the novice when he or she comes to grips with dominant and recessive inheritance and with homozygosity or heterozygosity. A criticism relevant to those readers outside the USA is that most of the legislation discussed (of patents, commercial law, state law etc) is relevant only in the USA.

Now I should come clean! A feeling that confronts me each time I dip into this book is that Professor Holtzman is telling us what should be done, not providing us with facts and a balanced discussion. In my view this is the major issue in medical genetics and ethics today. Everyone should be open about those matters which are within the individual's freedom of choice and that choice should be clear. Legal frameworks do give room for personal choice; those who survey the field have a responsibility to emphasise that fact. I would agree with and give high importance to many of Professor Holtzman's opinions. However, the barrage of his opinions - all mixed-up with the facts - means that the lay reader might be too punch-drunk to disagree!

I agree very much with the need for adequate provision of genetic counselling services ( $p$ 157). In the USA the medical care systems may well encourage diagnostic and laboratory facilities to be made available at the expense of those involving genetic counselling. Perhaps Holtzman envisages a more directive genetic counselling approach than would most geneticists.

In conclusion, Holtzman offers his own recommendations. These emphasise the inevitability of genetic screening, notwithstanding its dangers. Holtzman rightly stresses the need for community knowledge to be increased and for rigorous quality control.

What advice would I give to those who are involved in or interested in the ethics of genetic screening? Buy the paperback version. Do not read it through and through; use it as a source of information. Do not assume that Holtzman's conclusions must be agreed with; use them to provoke your own thoughts and ideas. Above all read other publications which impinge on this important topic for example: Wald $\mathrm{N}$, ed. Antenatal and Neonatal Screening. Oxford, Oxford University Press, 1984;
Warnock M. A Question of Life. Oxford, Basil Blackwell Ltd, 1985, and Church of Scotland. Abortion in Debate. Edinburgh, Quorum Press, 1987.

In fairness to Professor Holtzman, I am sure that such scepticism is exactly the response that he wishes.

SANDY RAEBURN, Professor of Clinical Genetics, Interdisciplinary Centre for Medical Genetics, City Hospital, Hucknall Road, Nottingham NG5 IPB.

\section{By What Right?: Studies in Medicine, Ethics and the Law}

Edited by Peter de Cruz and David

McNaughton, 73 pages, Newcastleunder-Lyme, $£ 7.00$, Penrhos

Publications, 1989

This book is the outcome of a weekend conference held in 1987 to mark the launching of a one-year part-time Diploma in Medical Ethics, which is offered by the Departments of Law and Philosophy at the University of Keele. All but one of the essays are revised versions of papers delivered at the conference. It is therefore to be expected that the contents of the book do not contribute to a single theme. There are five essays: The Leonard Arthur case by Peter de Cruz (doctor); Killing and letting die by David McNaughton (philosopher); Construction and working of a district hospital ethics committee by Christopher Rice (clinical lecturer); Human experimentation by Calliope Farsides (philosopher); The ethics of infertility treatment and embryo research by David Jabbari (lawyer). The essays all make interesting contributions individually, and no doubt it was a good conference. It is less obvious that the essays cohere as a unified book.

\section{R S DOWNIE,}

Professor of Moral Philosophy, Glasgow University.

\section{Undergraduate Medical Ethics Education}

F Baylis and J Downie, 142 pages, London, Ontario, Canada, \$8.95, Westminster Institute for Ethics and
Human Values, 1990

This book provides a useful survey of medical ethics education in the sixteen Canadian medical schools, and complements studies done in Britain, the United States and other countries. The survey was carried out in 1989 by the use of a wide-ranging questionnaire sent to each medical school.

Information was sought on the amount of ethics teaching, the curriculum and content, the stages in the undergraduate course that teaching took place, and the methods of teaching. This book summarises and tabulates the responses, and there emerges a mixed picture with some ethics being formally taught in all but one of the schools, but wide variation in both methods of teaching, curriculum time and content. Where ethics is taught there is also formal student evaluation, but methods of evaluation are equally diverse.

In conclusion, the study specifically reinforces many of the recommendations of the British Pond Report (1), emphasising the importance of ethics in health-care practice and pointing out the need for well-planned ethics teaching throughout the undergraduate course. Also needed is further training in medical ethics for many teachers, and multi-disciplinary co-operation in planning and carrying out the teaching.

This book will provide information on the various approaches that are being adopted in Canada, for those who are involved in teaching health care ethics to medical students. At a stage where the subject is developing rapidly this is a useful summary of the current position.

\section{Reference}

(1) Boyd K, ed. Report of a working party on the teaching of medical ethics: the Pond Report. London: IME Publications Ltd, 1987.

PROFESSOR RICHARD WEST, Medical Postgraduate Department, University of Bristol, Canynge Hall, Whiteladies Road, Bristol BS8 2PR.

\section{Birthrights: Law and Ethics at the Beginnings of Life}

Edited by Robert Lee and Derek Morgan, 222 pages, London, £9.99, Routledge, 1990 